\title{
Modeling the potential distribution of Valeriana carnosa Sm. in Argentinean Patagonia: A proposal for conservation and in situ cultivation considering climate change projections
}

\author{
Nicolás Nagahama ${ }^{\mathrm{a}, \mathrm{b}, \mathrm{c}, \star}$, Marcelo F. Bonino ${ }^{\mathrm{c}}$ \\ ${ }^{a}$ Estación Experimental Agroforestal Esquel (INTA), Esquel, Chubut, Argentina \\ ${ }^{\mathrm{b}}$ Facultad de Ciencias Naturales y Ciencias de la Salud, Universidad Nacional de la Patagonia San Juan Bosco, Esquel, Chubut, Argentina \\ ${ }^{\mathrm{c}}$ Consejo Nacional de Investigaciones Científicas y Técnicas (CONICET), San Carlos de Bariloche, Argentina
}

A R T I C L E I N F O

\section{Keywords:}

Climate change

Conservation

Medicinal plant

Patagonia

Species distribution

Sustainable use

\begin{abstract}
A B S T R A C T
Over recent years species distribution models have been used for the identification of suitable cultivation zones for native plant species. Valeriana carnosa is one of the most frequently used native plants in Patagonian popular medicine, its underground organs being obtained from natural populations. Considering the growing market demand, it is now necessary to design strategies for the cultivation and conservation of this valuable species. In this study, Ecological Niche Modeling (ENM) using the Maxent model was used to predict potential geographical distributions of $V$. carnosa under current and future climatic conditions and considering the projected climate changes for the next fifty years in Argentinean Patagonia. Results showed that by 2070 it is expected that $22 \%$ of the area with climatic conditions suited to $V$. carnosa will be lost. Most of these areas lie in the steppe region, and the remaining geographic areas with suitable climatic conditions will be found mainly in the Cordillera and PreCordillera regions. We identified five endangered $V$. carnosa populations in Patagonia. This study provides a novel tool for planning in situ cultivation of $V$. carnosa and preserving genetic material from endangered populations, considering the climate projections for the coming decades in Patagonia.
\end{abstract}

\section{Introduction}

The genus Valeriana L. is composed of some 250 species, widely distributed worldwide except for Australia and New Zealand, with South America constituting an important center of diversification (Hidalgo et al., 2004; Bell and Donoghue, 2005). Around the world several species of valerians are used for medicinal purposes, as their underground organs contain different compounds with sedative and relaxing properties, useful for the reduction of nervousness and stress (Nahrstedt, 1984).

Argentinean Patagonia holds 20 species of the genus Valeriana (Borsini, 1999; Kutschker, 2011). Among these, Valeriana carnosa Sm. (Valerianoideae, Caprifoliaceae) is one of the medicinal plants most frequently used by Patagonian regional ethnic and rural creole groups (Molares et al., 2018). This species grows in xeric, open, sunny environments on rocky or sandy soils of the forest, low sunny slopes of the Patagonian-Andean forest-steppe ecotone and in the highest mountains of the steppe region (Kutschker, 2011). It is an evergreen shrubby herb of up to $60 \mathrm{~cm}$ in height, ramified, with woody rhizomatous stems and thickened main roots (Fig. 1), and is distributed in Argentinean and Chilean Patagonia. For medicinal purposes only the underground parts of $V$. carnosa are used, its collection being an extractive and unsustainable practice. Moreover, all the raw material (roots and rhizomes) consumed by local people or sold in health food stores and herbalists is collected from wild populations (Estomba et al., 2006; Molares et al., 2018). In this context, considering growing market demand (Cuassolo, 2009; Cuassolo et al., 2010), the primary challenge is to prevent excessive gathering of wild plants; for the future, cultivation of this medicinal species is the only alternative able to meet the everincreasing demand of the phytotherapeutic industry (Schippmann et al., 2002).

Recently, Nagahama et al. (2019) proposed an agamic propagation method and sustainable management of $V$. carnosa, in order to stimulate in situ cultivation of this valuable phytomedicinal resource. For the design of long term in situ cultivation plans without artificial irrigation, it is essential to consider the suitable growing climate and the potential geographical distribution of $V$. carnosa in the future.

Ecological Niche Modeling (ENM) can help project the potential

\footnotetext{
* Corresponding author at: Estación Experimental Agroforestal Esquel (INTA), Esquel, Chubut, Argentina.

E-mail address: nagahama.nicolas@inta.gob.ar (N. Nagahama).
} 


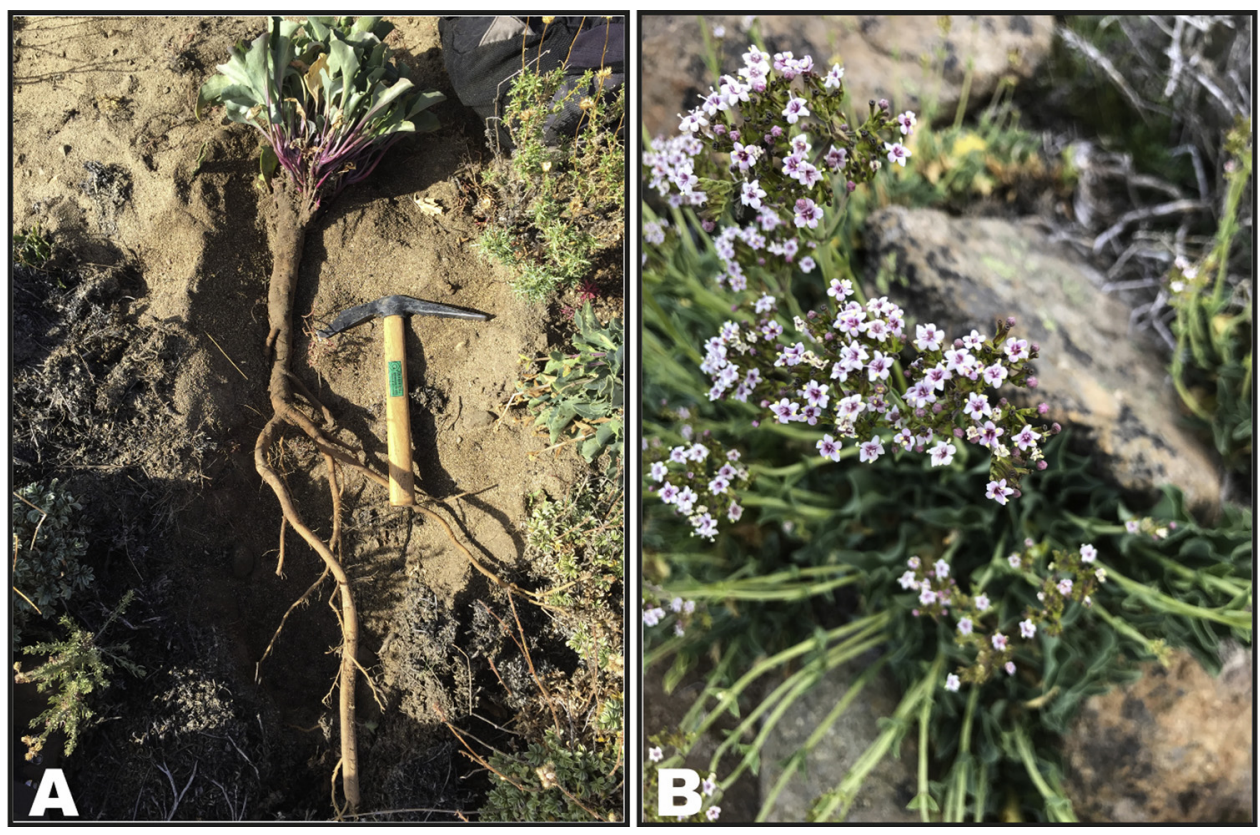

Fig. 1. Habit of V. carnosa. A, adult plant shows underground organs. B, detail of flowering plant.

geographic distribution of a species, and is a useful tool for a variety of applications in conservation biology (Ferrier, 2002); it is currently the most widely-used tool in ecology for evaluating the suitability of environments for biodiversity in the face of global warming (MoránOrdóñez et al., 2017). Many statistical models are currently used to simulate the spatial distribution of plant species (Adhikari et al., 2012), the spread of invasive species (Peterson et al., 2003) or the identification of suitable cultivation regions for medicinal plant species (Sharma et al., 2018; Li et al., 2019). Among the available algorithms, the maximum entropy (MaxEnt) is a machine- learning method designed for dealing with presence-only data (Phillips et al., 2006). The method requires environmental information such as topography, biogeography, climate and soil as predictor variables, and species occurrence data (Phillips and Dudik, 2008; Elith et al., 2011). It can make use of both continuous and categorical variables and incorporate interactions between them (Phillips et al., 2006); there are numerous successful examples of this model's application in predicting species distribution under different climate change scenarios (Fourcade et al., 2014; Alavi et al., 2019; Bouahmed et al., 2019). Another advantage of this model is the possibility of working with few presence records (Elith et al., 2006; Phillips et al., 2006), which is particularly relevant when working with rare species, for which few records are available.

Patagonia is a region characterized by its harsh climate (strong winds and low winter temperatures) and is inhabited by flora and fauna adapted to this climate. Much of Patagonia is altogether unprotected from livestock over-harvesting and anthropogenic degradation (Burkart et al., 2007). The main agricultural activity in Patagonia is extensive livestock farming, where natural grasslands are mainly used as a source of fodder for sheep (Golluscio et al., 1998). Only $4.7 \%$ of arid and semiarid Patagonia is protected to some degree, and $<1 \%$ is protected by the International Union for Conservation of Nature (IUCN) level I, II, or III reserves (Burkart et al., 2007). V. carnosa is preferred by livestock, therefore, out of the protected areas in Patagonia, the plants survive in places where livestock cannot access, as in rocky cliffs or un-grazing paddocks.

Climatic variation in Patagonia has recently been related to global climate change; for example, a reduction in rainfall and increasing temperature has led to glacier recession, resulting in reduced river flow over the Andes Mountains (Barros et al., 2015). Moreover, there has been general warming, such that both maximum and minimum temperatures have shown an upward trend in the second half of the past century in Patagonia (Hoffmann et al., 1997; Barros et al., 2015). According to these scenario projections, the negative precipitation trend observed over the last century is also projected to continue in north Patagonia, and most of the projected precipitation reductions are likely to occur in winter (Barros et al., 2015). Although it is recognized that climatic fluctuations may affect ecosystems, communities and organisms (Parmesan et al., 2000; Meserve et al., 2003), our knowledge of environmental factors affecting the Patagonian flora is limited. On this basis, predicting the potential distribution of $V$. carnosa under different climate scenarios and understanding its preferred habitat in Patagonia are of great significance for its conservation and in situ cultivation program design, and will enable us to predict how climate change could affect the natural distribution of this plant species.

In this study we used ENM to identify: 1- endangered populations of $V$. carnosa according to the climate projections of the coming decades, and 2- potential geographical areas for in situ cultivation of $V$. carnosa in present and future climatic conditions. This will contribute both to the conservation of this native species and to the development of a nontraditional sustainable economic activity for Argentinean Patagonia. Finally, this study aims to show how ENM considering climate change projections could be used to design cultivation and conservation strategies that can address the market demand for uncultivated native plants in other regions around the world.

\section{Material and methods}

\subsection{Study area}

Argentinean Patagonia displays a cold temperate climate, humid towards the Andean region in the west (more than $1000 \mathrm{~mm}$ of annual precipitation) and arid in the extra-Andean region in the east (less than $150 \mathrm{~mm}$ average annual rainfall; Garreaud et al., 2009). The rainy season coincides with the coldest months of the year (Jobbágy et al., 1995; Paruelo et al., 1998, 2000). V. carnosa grows between latitudes $-36^{\circ}$ and $-55^{\circ}$, mainly in the Andean region, but also in some isolated populations that can be found in the extra-Andean region. 




Fig. 2. Current distribution of $V$. carnosa. A-I, different ecosystems where $V$. carnosa lives in Argentinean Patagonia. A, mountain forest in northwest Neuquén. B, Araucaria araucana forest in central west Neuquén. C, pre-cordillera ecotone in northwest Chubut. D, periglacial forest in southwest Santa Cruz. E, Patagonian steppes in South Santa Cruz. F, highest mountain of extra-Andean Patagonia in north Chubut (La Buitrera). G, mountain forest in south west Chubut. H, rocky walls in coastal steppes of north east Santa Cruz. I, coastal zone in south east Tierra del Fuego. J, Potential predicted distribution of V. carnosa in southern Argentina. Filled circles indicate sample points (populations). Coloured areas represent "presence areas", the resulting output reclassified to convert the continuous output into a map of presence-absence (0-1) using a Minimum Training Presence (MTP) threshold. The red square indicates the locality registered for a herbarium specimen of $V$. carnosa collected in 1946 (BAB, A. Soriano 2020), not found nowadays.

\subsection{Species occurrence data}

Occurrence records of $V$. carnosa were mainly obtained through georeferenced points during fieldwork carried out between 2015 and 2017 (52 data points) and detailed bibliographic surveys (13 data points) from $B A B$ herbarium and literature (Kutschker, 2011; Kutschker and Morrone, 2012; Fig. 2). Data were filtered by removing any unreliable locality or uncertain species determination and which that are less than $1 \mathrm{~km}$ away from each other. Collection sites registered in herbarium specimens collected more than 50 years ago, or in the extraAndean region, were visited during field trips between 2017 and 2018 to confirm the presence of $V$. carnosa. In only in one of these localities was the taxon not found (Fig. 2). This site, known as Pampa del Castillo, has the highest elevation in the southeast of Chubut province, and $V$. carnosa was collected in 1946 at $420 \mathrm{~m}$ a.s.l. (voucher specimen $A$. Soriano 2020, from BAB Herbarium). Finally, we retained 58 occurrence data for niche modeling analysis.

\subsection{Niche modeling procedures}

To estimate the potential distribution range of $V$. carnosa, or more precisely, the area of current climate suitability, we used Ecological Niche Models (ENMs) with MaxEnt (Phillips et al., 2006), shown to be a robust method for presence-only datasets (Elith et al., 2006; Pyron et al., 2008).

We used 21 environmental variables: 19 bioclimatic variables, obtained from the global meteorological database (Fick and Hijmans, 2017), plus elevation and slope at $1 \mathrm{~km} \times 1 \mathrm{~km}$ resolution. All layers were clipped to the calibration area, defined as a region of the world that has been accessible to the species via dispersal over relevant periods of time. In this study, since the goal was to identify suitable areas for the regional exploitation of V. carnosa, we clipped Southern Argentina.

This calibration area was defined according to the theoretical BioticAbiotic-Mobility approach (BAM) proposed by Soberón and Peterson (2005), which captures and links the geographic and environmental dimensions of species distributions (Peterson et al., 2008). We did a pairwise Pearson correlation between the 21 variables for a random 
sample of 1000 points across the study area, selecting the variables that did not show collinearity with other variables $(r<0.75)$. Variables retained were 1- Mean diurnal range, 2- Isothermality, 3- Temperature seasonality, 4- Maximum temperature of warmest month, 5- Minimum temperature of coldest month, 6- Mean temperature of driest quarter, 7Annual precipitation, 8- Precipitation seasonality, 9- Precipitation of coldest quarter, 10- Elevation and 11- Slope.

To project the future potential distribution range, we considered the RCP 6.0 (Representative Concentration Pathways) scenario for year 2070 (2060-2080) proposed by The Intergovernmental Panel on Climate Change (IPCC), since this is an "intermediate" scenario in terms of severity. We consider that extreme scenarios are less likely, therefore we selected the RCP 6.0 scenario which represents a conservative view in terms of probabilities and may be more realistic. Due to the uncertainty introduced by different Atmosphere-Ocean Global Circulation Models (AOGCMs) for future conditions (Diniz-Filho et al., 2009; Nori et al., 2011), and to cover the range of variation among these, we selected three different AOGCMs: CCSM4 (Community Climate System Model, version 4), CGCM4 (Fourth Generation Atmospheric General Circulation Model) and HadGEM2 (Hadley Centre Global Environmental Model, version 2), which have different equilibrium climate sensitivity values. We worked with the average of the bioclimatic variables of these three AOGCMs.

To evaluate model performance in $V$. carnosa, we used the area under the curve (AUC) of the Receiver Operating Characteristics (ROC) curve. AUC shows the proportion of correctly and incorrectly classified predictions over a range of probability thresholds (Pearce and Ferrier, 2000). The AUC is widely used to assess species distribution models (SDM), with values above 0.5 indicating a performance better than random (Peterson et al., 2008). We considered AUC values of $0.5-0.7$ to indicate low accuracy, 0.7-0.9 indicative of moderate (good) accuracy, and > 0.9 indicative of high accuracy (Swets, 1988; Manel et al., 2001). Due to the limitations of the ROC approach mentioned by Lobo et al. (2008), we also used a partial ROC-AUC approach (Peterson et al., 2008). To analyze the contribution of the different variables in construction of the models, we used "Analysis of Variable Contributions" and "Jackknife" performed by MaxEnt. In the "Analysis of Variable Contributions" to determine the first estimate, in each iteration of the training algorithm, the increase in regularized gain is added to the contribution of the corresponding variable, or subtracted from it if the change to the absolute value of lambda is negative. For the second estimate, for each environmental variable in turn, the values of that variable on training presence and background data are randomly permuted. The model is reevaluated on the permuted data, and the resulting drop in training AUC is shown in Table 2 (normalized to percentages).

The projections obtained with MaxEnt were reclassified to convert the continuous output in a presence/absence (0-1) map using a Minimum Training Presence (MTP) threshold. This threshold finds the lowest predicted suitability value for an occurrence point that prevents omission of known localities on output maps; in other words, this threshold ensures that all occurrence points fall within the area of the binary model, making it a conservative criterion. Finally, we obtained the total potential distribution area, northern and southern latitude limits (the extreme latitudes of the projected distribution), and altitude limits (the highest and lowest altitude of the projected distribution). From these parameters we calculated the stable area: the portion of the original geographic area remaining with suitable climatic conditions, corresponding to the overlap between future and present maps of potential distributions.

Since model run with 58 occurrence data, the Maxent output summarizes the results of a maximum of 57-fold cross-validation (57 replicates), and all results shown were obtained from the average output of model runs.

\section{Results}

\subsection{Predicting the distribution of V. carnosa under current climatic conditions}

We found average test AUC values greater than 0.95 for the MaxEnt output (Test AUC $=0.97 \pm 0.01$ ), indicating high accuracy in the predictive capacity of the model. Additionally, the partial ROC statistics were highly significant $(\mathrm{p}<0.001)$, indicating the high reliability of the models (Fig. S1).

The potential distribution range of $V$. carnosa in current climatic conditions includes a total of $167505 \mathrm{~km} 2$, the greater part of which lies in the Cordillera and Pre-Cordillera (west Patagonia) zones, and in the extra-Andean zone in southern Patagonia, at elevations generally between 0 and $2500 \mathrm{~m}$ a.s.l. (Fig. 2).

\subsection{How would climate change affect V. carnosa habitat preference in Patagonia?}

In the future, $22 \%$ of the area with adequate climatic conditions, belonging mainly to steppe areas (extra-Andean Patagonia), is expected to be lost. The remaining portion with suitable climatic conditions for the future (stable area) is $67.8 \%$, mainly in the Cordillera and PreCordillera zones (Fig. 3). The current and future potential distribution area of $V$. carnosa, northern and southern latitude limits, altitude limits and stable area are summarized in Table 1 . Based on the potential distribution range of $V$. carnosa in future conditions, we identified four endangered populations: two in the northernmost Andean region and two located in the extra-Andean region of central Patagonia (Fig. 3).

\subsubsection{The contribution of environmental variables}

According to the analysis of variable contributions performed by MaxEnt, the variables that contributed most to construction of the model were maximum temperature of warmest month (40.9\%), precipitation of coldest quarter (24.5\%), Slope (14.2\%), temperature seasonality $(7.3 \%)$ and Elevation $(6.4 \%)$. All other variables together contributed less than $10 \%$ (Table 2). In the Jackknife test of variable importance, maximum temperature of warmest month showed the highest gain when used in isolation, and therefore appears to have the most useful information by itself (Fig. 4). The environmental variable that most reduced the gain when omitted was Slope, which therefore appears to have the most information not present in the other variables. Values shown are averages over replicate runs. The range within which the climatic-environmental variable generates the highest prediction values in MaxEnt (response curves, cumulative output $>90$ ) is where the maximum temperature of warmest month is lower than $18^{\circ} \mathrm{C}$ and precipitation of coldest quarter is high ( $>400 \mathrm{~mm}$ ).

\section{Discussion}

Advances in global circulation model (GCM) studies has enabled the generation of projections suggesting that the global mean surface temperature will increase over the next century (Pachauri and Reisinger, 2007). This increase in global temperature is also associated with changes in precipitation and $\mathrm{CO} 2$ concentration, among others, modifying environmental conditions and influencing the distribution of plant species (Rivaes et al., 2014; Li et al., 2019). It has been estimated that environmental conditions in Patagonia will be strongly affected by global climate change (Barros et al., 2015) and therefore, as seen in the results obtained in this study, the distribution of V. carnosa will also be affected.

Results from the Analysis of Variable Contributions and the Jackknife test of Variable Importance showed that the variables contributing most to construction of the model were maximum temperature of warmest month, followed by precipitation of coldest quarter, and Slope. The range within which the climatic-environmental variable 

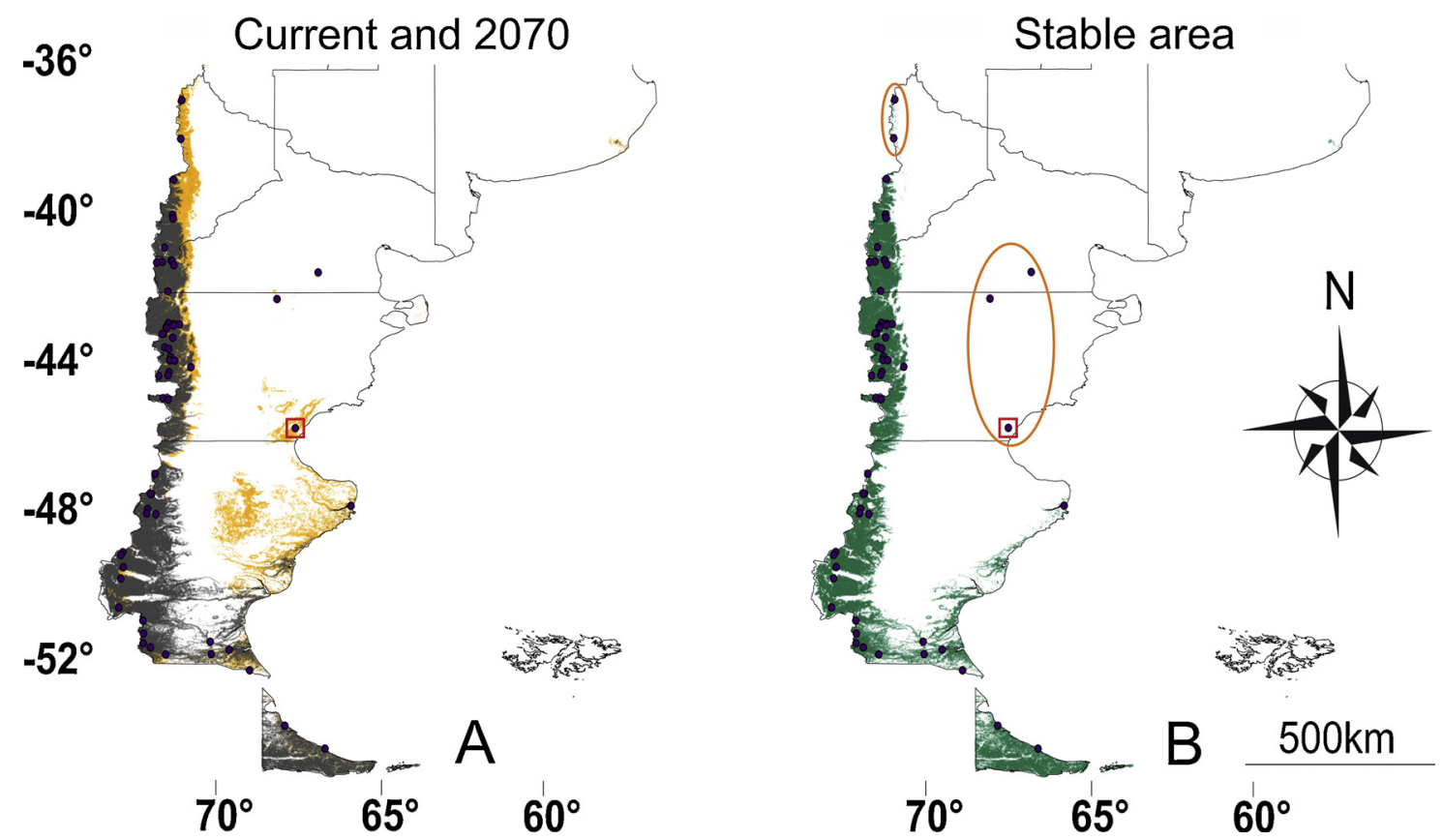

Fig. 3. Potential current and predicted distribution of $V$. carnosa in southern Argentina, considering the RCP 6.0 scenario. A, current (orange) and year 2070 (dark grey); B, stable area (green). Orange circles indicate the endangered populations that could disappear in the next years. Filled circles indicate the sample points (populations). Coloured areas represent "presence areas", the resulting output reclassified to convert the continuous output into a map of presence-absence (0-1) using a Minimum Training Presence (MTP) threshold. The red squares indicate the locality registered as a herbarium specimen of $V$. carnosa collected in 1946 (BAB, A. Soriano 2020), not found nowadays.

Table 1

Projection parameters for current conditions, year 2070 and stable area, considering RCP 6.0 emission scenario for the future proposed by the IPCC (2013). PR potential range, NLL north latitudinal limit, SLL south latitudinal limit, LR latitudinal range, LAL lower altitudinal limit, HAL higher altitudinal limit.

\begin{tabular}{llll}
\hline & Current & 2070 & Stable area \\
\hline $\mathrm{PR}\left(\mathrm{km}^{2}\right)$ & 167505 & 130696 & 113495 \\
$\mathrm{NLL}$ & $-30.70^{\circ}$ & $-36.67^{\circ}$ & $-36.67^{\circ}$ \\
$\mathrm{SLL}$ & $-55.05^{\circ}$ & $-55.05^{\circ}$ & $-55.05^{\circ}$ \\
$\mathrm{LR}$ & $24.34^{\circ}$ & $18.38^{\circ}$ & $18.38^{\circ}$ \\
$\mathrm{LAL}(\mathrm{m}$ a.s.l.) & 0 & 0 & 0 \\
HAL (m a.s.l.) & 2921 & 2617 & 2604 \\
\hline
\end{tabular}

generates the highest prediction values in MaxEnt is where the maximum temperature of warmest month is lower than $18{ }^{\circ} \mathrm{C}$ and precipitation of coldest quarter is higher than $400 \mathrm{~mm}$. These temperature values are lower than the real values observed for sites where $V$. carnosa populations can currently be found, which suggests that the data obtained from the modeling are associated with some uncertainty. For example, the cumulative output is near zero when the maximum temperature of warmest month values are higher than $25^{\circ} \mathrm{C}$, indicating an abrupt fall in environmental quality when the maximum temperatures of the environment increase, possibly reflecting the sensitivity of this species to this variable. This difference between the temperature obtained by modeling and the real temperature at sites where $V$. carnosa is present could be explained by the scarcity of meteorological stations in Patagonia, the poor precision or high level of uncertainty of bioclimatic data for the region, the amount of bioclimatic data from Wordclim (50 years) and/or the modeling itself. Regardless of the values, the most important result is identification of the variables that contribute most to construction of the model. Based on these inconsistencies, experimental field observations and MODIS temperature data (Wan et al., 2015; ORNL DAAC, 2017), it is likely that the thermal threshold for V. carnosa is higher than that estimated by MaxEnt. For the purpose of this work, this underestimation of the results makes application of the tool more robust, since it ensures that the areas identified as viable may have a certain safety margin if climatic changes turn out to be even more radical than those predicted under the RCP 6.0 scenario. It would be interesting to calibrate bioclimatic data with real meteorological data, but this is beyond the scope of this study.

Table 2

Analysis of variable contributions. Relative contributions of the environmental variables in predicting the current distribution of $V$. carnosa using MaxEnt. Values shown are averages over 57 replicate runs.

\begin{tabular}{|c|c|c|c|}
\hline Variable code & Variable detail & Percent contribution (\%) & Permutation importance \\
\hline argbio5 & Maximum temperature of warmest month $\left({ }^{\circ} \mathrm{C}\right)$ & 40.9 & 68.7 \\
\hline argbio19 & Precipitation of coldest quarter (mm) & 24.5 & 0.4 \\
\hline slope_arg & Slope $(\%)$ & 14.2 & 6.2 \\
\hline argbio4 & Temperature seasonality $\left({ }^{\circ} \mathrm{C}\right)$ & 7.3 & 7.4 \\
\hline elev_dem_arg & Elevation (m a.s.l.) & 6.4 & 5.3 \\
\hline argbio2 & Mean diurnal range $\left({ }^{\circ} \mathrm{C}\right)$ & 2.5 & 0.5 \\
\hline argbio12 & Annual precipitation (mm) & 2.4 & 5 \\
\hline argbio15 & Precipitation seasonality (mm) & 1 & 2.5 \\
\hline argbio6 & Minimum temperature of coldest month $\left({ }^{\circ} \mathrm{C}\right)$ & 0.4 & 3.2 \\
\hline argbio3 & Isothermality $\left({ }^{\circ} \mathrm{C}\right)$ & 0.4 & 0.7 \\
\hline argbio9 & Mean temperature of driest quarter $\left({ }^{\circ} \mathrm{C}\right)$ & 0.1 & 0.3 \\
\hline
\end{tabular}




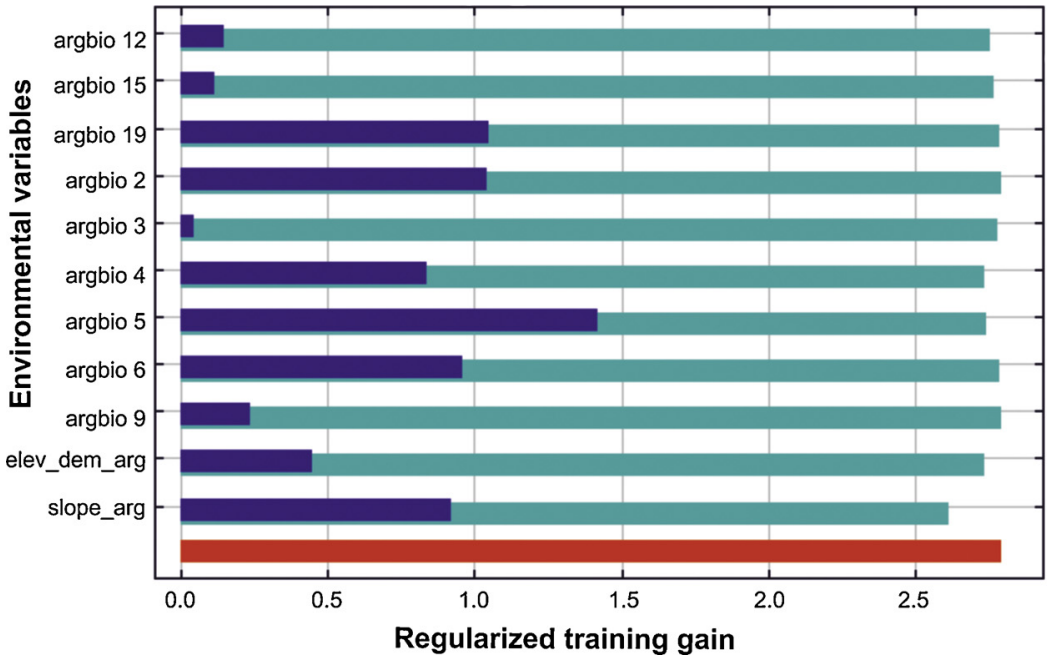

Without variable With only variable With all variables
Fig. 4. Jacknife of regularized training gain. The following picture shows the results of the Jackknife test of relative importance of environmental variables for $V$. carnosa in Patagonia. Values shown are averages over replicate runs.

Key: "argbio5", Maximum Temperature of Warmest Month; "argbio19", precipitation of coldest quarter; "slope_arg", slope; "argbio4", Temperature Seasonality; "elev_dem_arg", elevation; "argbio2", Mean Diurnal Range; “argbio12”, annual precipitation; "argbio15”, precipitation seasonality; "argbio6", Minimum Temperature of Coldest Month; “argbio3", isothermality; "argbio9", mean temperature of driest quarter. Without variable (light blue), with only variable (blue), with all variables (red).
At present, field observations show the most numerous and extensive $V$. carnosa populations in the western region of Argentinean Patagonia, which coincides with the areas with the best climate characteristics obtained by ENM. However, there are also isolated populations to the east in the Patagonian steppe, particularly in the highest mountains of extra-Andean Patagonia. These populations are generally located in areas of high elevation (between $1600-1900 \mathrm{~m}$ a.s.l.) and low solar exposure, associated with rocky walls at least in the extraAndean region of north Patagonia. This coincides with the variable that contributed most to construction of the model, maximum temperature of warmest month, which was negatively related to habitat suitability. Representative species of mountain flora from the Andes region can also be found at these high-altitude points, as the vegetation is completely different to the lower areas of the Patagonian steppes. These particular ecosystems, modeled mainly by climatic conditions associated with high altitude, are very fragile, and this is reflected in the modeling projections.

La Buitrera population (Fig. $2 \mathrm{~F}$ ) is located at the top of the highest mountain of extra-Andean Patagonia, at $1893 \mathrm{~m}$ a.s.l., and was predicted to lie outside the modeling prediction stable area. Previous studies have shown that with global warming, some species will migrate to high latitude or high elevation (Fordham et al., 2012; Telwala et al., 2013; Zhang et al., 2018); however, in extra-Andean Patagonia, since plants are already at the highest points (mountain top), these populations are at risk of extinction. Another example related to the distribution of $V$. carnosa and temperature can be observed in the southern region of Patagonia, due to a higher latitude (lower temperature), where populations can even be observed in stable areas on the Atlantic coast. The negative effect of high temperature was also observed for plantlets in experimental conditions, such that prolonged exposure to temperatures above $40{ }^{\circ} \mathrm{C}$ caused wilting and plant death (Nagahama et al., 2019). Therefore, areas east of -70.83 longitude in north Patagonia (a region with temperatures higher than $40^{\circ} \mathrm{C}$ in summer and low precipitation in winter) are not recommended for in situ cultivation of $V$. carnosa. In addition, populations currently inhabiting these areas are the most likely to disappear.

In a previous study we observed that for the efficient propagation and seedling survival of $V$. carnosa it is necessary to have a good drainage substratum, since intense irrigation and excessive moisture of the substrate caused the progressive rotting of roots (Nagahama et al., 2019). This requirement could be related to the third variable contributing markedly to construction of the model (Slope), directly associated with soil waterlogging.

Study of the interaction between a species and its environment is an essential aspect of species cultivation. Li et al. (2019) predicted the distribution of other Valerianaceae species of medicinal importance from China (Nardostachys jatamansi and $N$. chinensis), and they provide theoretical guidance for its cultivation, considering the effects of climate change. These authors suggest that for habitat prediction of $N$. jatamansi and $N$. chinensis in China, precipitation was the largest contributing factor when modeling the distributions (Li et al., 2019). In Patagonia we observed that precipitation during the coldest quarter was an important variable, contributing greatly to construction of the distribution model in $V$. carnosa.

In this study, according to the ENM, the areas with the best climatic characteristics for in situ cultivation of $V$. carnosa lie in the west of Argentinean Patagonia, in the Andes mountain range. Considering the uncertainty associated with projected climate change forecasts for the coming decades, it is recommended that in situ cultivation and future breeding programs be conducted within the stable areas, i.e., the geographical areas obtained in this work that would still provide adequate conditions for establishment of V. carnosa, at least through 2070.

Guajardo et al. (2018) suggest there is chemotypic variability (quantitative and qualitative) between different populations of $V$. carnosa in Patagonia. According to future climate scenario modeling, two $V$. carnosa populations in northern Patagonia (Fig. 3) and three populations located in the extra-Andean zone of central Patagonia could disappear over the next decades. It is therefore important to conserve germplasm from these populations in ex situ nurseries within the stable areas.

The collection site of the herbarium specimen collected in 1946 ( $A$. Soriano 2020) was located within the potential distribution range in current climatic conditions. However, plants have not been registered there at present (Fig. 3), which could indicate that the fluctuations in climatic conditions registered over the last years in Patagonia (Hoffmann et al., 1997; Barros et al., 2015) could have affected the survival of $V$. carnosa in this low-altitude geographic area, which is dry and experiences high temperatures.

\section{Conclusions}

Based on this study, we propose ENM as a tool to identify potential areas for cultivating $V$. carnosa without artificial irrigation, so as to encourage the conservation and sustainable use of this species in Argentinean Patagonia. These areas lie between -38.50 and -51.58 latitude, to the west of -70.83 longitude (excluding some isolated pixels), and in most of the areas south of -51.58 latitude, in southern Argentina. It is recommended that when selecting areas, temperatures in the warm months should not exceed $40^{\circ} \mathrm{C}$, the rains in the cold months should be abundant $(>400 \mathrm{~mm}$ ) and plants should be cultivated on sloping land or well-drained soils. In situ cultivation of $V$. carnosa will help in the conservation of natural populations, the 
provision of this species for self-consumption, and the authenticity of the plant material (commercial raw material). We identified four endangered populations of $V$. carnosa that should be included in conservation strategies using ex situ nurseries. Based on the results obtained, we propose that the area inhabited by the La Buitrera population should be declared a protected area. This would prevent the degradation currently generated by overgrazing and anthropic activity, thus reducing pressure factors on this particular ecosystem that is already highly vulnerable due to climate change. Finally, in this work we show how Ecological Niche Modeling can be very useful, complemented by other approaches, in the planning of native species cultivation considering the effects of climate change, and how this tool could also be used to design territorial ordering strategies.

\section{Declaration of Competing Interest}

None.

\section{Acknowledgements}

This work was supported by ANPCYT (PICT 2014-3149), INTA (PNHFA 1106094) and CONICET. We are grateful to Audrey Shaw for correcting the English version. We are grateful to Dirección de Fauna y Flora Silvestre of Chubut, Argentina. A special thanks to Dr. María M. Manifesto and Dr. Reneé H. Fortunato (Instituto de Recursos Biológicos, CIRN- INTA, Hurlingham, Buenos Aires, Argentina) for helpful comments. Many thanks to all members of the Natural Resources Group of EEA INTA Esquel.

\section{Appendix A. Supplementary data}

Supplementary material related to this article can be found, in the online version, at doi:https://doi.org/10.1016/j.jarmap.2020.100240.

\section{References}

Adhikari, D., Barik, S.K., Upadhaya, K., 2012. Habitat distribution modelling for reintroduction of Ilex khasiana Purk., a critically endangered tree species of northeastern India. Ecological Engineering 40, 37-43. https://doi.org/10.1016/j.ecoleng. 2011.12.004.

Alavi, S.J., Ahmadi, K., Hosseini, S.M., Tabari, M., Nouri, Z., 2019. The response of English yew (Taxus baccata L.) to climate change in the Caspian Hyrcanian Mixed Forest ecoregion. Regional Environmental Change 19 (5), 1495-1506. https://doi. org/10.1007/s10113-019-01483-x.

Barros, V.R., Boninsegna, J.A., Camilloni, I.A., Chidiak, M., Magrín, G.O., Rusticucci, M., 2015. Climate change in Argentina: trends, projections, impacts and adaptation. WIREs Climate Change 6, 151-169. https://doi.org/10.1002/wcc.316.

Burkart, R., Carpinetti, B., Molinari, R., Carminati, A., Martín, G., Balabusic, A., Raffo, L., Machain, N., Almirón, M., Paz Barreto, D., et al., 2007. Las áreas protegidas de la Argentina. Herramienta superior para la conservación de nuestro patrimonio natural y cultural. Administración de Parques Nacionales, BuenosAires. http://refhub. elsevier.com/S0140-1963(13)00221-8/sref13.

Bell, C.D., Donoghue, M.J., 2005. Phylogeny and biogeography of Valerianaceae (Dipsacales) with special reference to the South American valerians. Organisms Diversity \& Evolution 5 (2), 147-159. https://doi.org/10.1016/j.ode.2004.10.014.

Borsini, O.E., 1999. Valerianaceae. In: Correa, M.N. (Ed.), Flora Patagónica Parte VI. Colección Científica Instituto Nacional de Tecnología Agropecuaria, Buenos Aires, pp. 448-471.

Bouahmed, A., Vessella, F., Schirone, B., Krouchi, F., Derridj, A., 2019. Modeling Cedrus atlantica potential distribution in North Africa across time: new putative glacial refugia and future range shifts under climate change. Regional Environmental Change 19, 1667-1682. 10.1007\%2Fs10113-019-01503-w.

Cuassolo, F., 2009. Estudio etnobotánico de las plantas medicinales nativas y exóticas comercializadas en la ciudad de Bariloche (Patagonia, Argentina). Thesis degree. Universidad Nacional del Comahue.

Cuassolo, F., Ladio, A., Ezcurra, C., 2010. Aspectos de la comercialización y control de calidad de las plantas medicinales más vendidas en una comunidad urbana del NO de la Patagonia Argentina. Boletín Latinoamericano y del Caribe de Plantas Medicinales y Aromáticas 9 (3), 165-176.

Diniz-Filho, J.A.F., Bini, M.L., Rangel, F.T., Loyola, R.D., Hof, C., Nogués-Bravo, D., Araújo, M.B., 2009. Partitioning and mapping uncertainties in ensembles of forecasts of species turnover under climate change. Ecography 32 (6), 897-906. https://doi. org/10.1111/j.1600-0587.2009.06196.x.

Elith, J., Graham, C.H., Anderson, R.P., Dudík, M., Ferrier, S., Guisan, A., Hijmans, R.J., Huettmann, F., Leathwick, J.R., Lehmann, A., Li, J., Lohmann, L.G., Loiselle, B.A.,
Manion, G., Moritz, C., Nakamura, M., Nakazawa, Y., Overton, J.M.C., Peterson, A.T., Phillips, S.J., Richardson, K.S., Scachetti-Pereira, R., Schapire, R.E., Soberón, J., Williams, S., Wisz, M.S., Zimmermann, N.E., 2006. Novel methods improve prediction of species' distributions from occurrence data. Ecography 129-151. https://doi. org/10.1111/j.2006.0906-7590.04596.x.

Elith, J., Phillips, S.J., Hastie, T., Dudík, M., Chee, Y.E., Yates, C.J., 2011. A statistica explanation of MaxEnt for ecologists. Diversity and Distributions 17 (1), $43-57$. https://doi.org/10.1111/j.1472-4642.2010.00725.x.

Estomba, D., Ladio, A., Lozada, M., 2006. Medicinal wild plant knowledge and gathering patterns in a Mapuche community from North-western Patagonia. Journal of Ethnopharmacology 103 (1), 109-119. https://doi.org/10.1016/j.jep.2005.07.015.

Ferrier, S., 2002. Mapping spatial pattern in biodiversity for regional conservation planning: where to from here? Systematic Biology 51 (2), 331-363.

Fick, S.E., Hijmans, R.J., 2017. WorldClim 2: new 1-km spatial resolution climate surfaces for global land areas. International Journal of Climatology 37 (12), 4302-4315. https://doi.org/10.1002/joc.5086.

Fordham, D.A., Resit Akçakaya, H., Araújo, M.B., Elith, J., Keith, D.A., Pearson, R., et al., 2012. Plant extinction risk under climate change: are forecast range shifts alone a good indicator of species vulnerability to global warming? Global Change Biology 18 (4), 1357-1371. https://doi.org/10.1111/j.1365-2486.2011.02614.x.

Fourcade, Y., Engler, J.O., Rödder, D., Secondi, J., 2014. Mapping species distributions with MAXENT using a geographically biased sample of presence data: a performance assessment of methods for correcting sampling bias. PLoS One 9 (5), e97122. https:// doi.org/10.1371/journal.pone.0097122.

Garreaud, R.D., Vuille, M., Compagnucci, R., Marengo, J., 2009. Present-day South American climate. Palaeogeography, Palaeoclimatology, Palaeoecology 281 (3-4), 180-195.

Golluscio, R., Deregibus, A., Paruelo, J., 1998. Sustainability and management in the Patagonian steppes. Ecología Austral 8, 265-284.

Guajardo, J.J., Gastaldi, B., González, S.B., Nagahama, N., 2018. Variability of phenolic compounds at different phenological stages in two populations of Valeriana carnosa Sm. (Valerianoideae, Caprifoliaceae) in Patagonia. Boletin Latinoamericano y del Caribe de Plantas Medicinales y Aromáticas 17, 381-393.

Hidalgo, O., Garnatje, T., Susanna, A., Mathez, J., 2004. Phylogeny of Valerianaceae based on matK and ITS markers, with reference to matK individual polymorphism. Annals of Botany 93 (3), 283-293. https://doi.org/10.1093/aob/mch042.

Hoffmann, J., Nuñez, S., Vargas, W., 1997. Temperature, humidity and precipitation variations in Argentina and the adjacent sub-antartic region during the present century. Meteorologische Zeitschrift 6, 3-11.

Jobbágy, E.G., Paruelo, J.M., León, R.J., 1995. Estimación del régimen de precipitación a partir de la distancia a la cordillera en el noroeste de la Patagonia. Ecología Austral 5 (1), 47-53.

Kutschker, A., 2011. Revisión del género Valeriana (Valerianaceae) en Sudamérica austral. Gayana Botanica 68 (2), 244-296. https://doi.org/10.4067/S071766432011000200016.

Kutschker, A., Morrone, J.J., 2012. Distributional patterns of the species of Valeriana (Valerianaceae) in southern South America. Plant Systematics and Evololution 298, 535-547. https://doi.org/10.1007/s00606-011-0564-6.

Li, J., Wu, J., Peng, K., Fan, G., Yu, H., Wang, W., He, Y., 2019. Simulating the effects of climate change across the geographical distribution of two medicinal plants in the genus Nardostachys. PeerJ 7, e6730. https://doi.org/10.7717/peerj.6730.

Lobo, J.M., Jiménez-Valverde, A., Real, R., 2008. AUC: a misleading measure of the performance of predictive distribution models. Global Ecology and Biogeography 17 (2), 145-151. https://doi.org/10.1111/j.1466-8238.2007.00358.x.

Manel, S., Williams, H.C., Ormerod, S.J., 2001. Evaluating presence-absence models in ecology: the need to account for prevalence. Journal of Applied Ecology 38, 921-931. https://doi.org/10.1046/j.1365-2664.2001.00647.x.

Meserve, P.L., Kelt, D.A., Milstead, W.B., Gutiérrez, J.R., 2003. Thirteen years of shifting top-down and bottom-up control. Bioscience 53, 633-646.

Molares, S., Ladio, A.H., Nagahama, N., 2018. Recent reports on ethnopharmacological and ethnobotanical studies of Valeriana carnosa Sm. (Valerianaceae). In: Martinez, J.L., Munoz-Acevedo, A., Rai, M. (Eds.), Ethnobotany: Local Knowledge and Traditions. CRC Press, Boca Raton, pp. 90-102.

Morán-Ordóñez, A., Lahoz-Monfort, J.J., Elith, J., Wintle, B.A., 2017. Evaluating 318 continental-scale species distribution models over a 60-year prediction horizon: what factors influence the reliability of predictions? Global Ecology and Biogeography 26, 371-384. https://doi.org/10.1111/geb.12545.

Nagahama, N., Manifesto, M.M., Fortunato, R.H., 2019. Vegetative propagation and proposal for sustainable management of Valeriana carnosa Sm., a traditional medicinal plant from Patagonia. Journal of Applied Research on Medicinal and Aromatic Plants 14, 100218. https://doi.org/10.1016/j.jarmap.2019.100218.

Nahrstedt, A., 1984. Drugs and phytopharmaca having sedative activity. Deutsche Apotheker-Zeitung 124 (24), 1213-1216.

Nori, J., Urbina-Cardona, J.N., Loyola, R.D., Lescano, J.N., Leynaud, G.C., 2011. Climate change and American bullfrog invasion: what could we expect in South America? PLoS One 6 (10), e25718. https://doi.org/10.1371/journal.pone.0025718.

ORNL DAAC (Oak Ridge National Laboratory Distributed Active Archive Center), 2017. Spatial Data Access Tool (SDAT). Available at https://doi.org/10.3334/ ORNLDAAC/1388 (Accessed 18 December 2018).

Pachauri, R.K., Reisinger, A., 2007. Climate Change 2007: Synthesis Report. Contribution of Working Groups I, II and III to the Fourth Assessment Report of the Intergovernmental Panel on Climate Change. IPCC, Geneva.

Parmesan, C., Root, T.L., Willig, M.R., 2000. Impacts of extreme weather and climate on terrestrial biota. Bulletin of the American Meteorological Society 81, 443-450. https://doi.org/10.1175/1520- 0477(2000)081 \0443:IOEWAC[2.3.CO;2.

Paruelo, J.M., Sala, O.E., Beltrán, A.B., 2000. Long-term dynamics of water and carbon in 
semi-arid ecosystems: a gradient analysis in the Patagonia steppe. Plant Ecology 150, 133-143.

Paruelo, J.M., Beltrán, A.B., Sala, O.E., Jobbagy, E.G., Golluscio, R.A., 1998. The climate of Patagonia: general patterns and controls on biotic processes. Ecología Austral 8, 85-104.

Pearce, J., Ferrier, S., 2000. Evaluating the predictive performance of habitat model developed using logistic regression. Ecological Modelling 133 (3), 225-245. https:// doi.org/10.1016/S0304-3800(00)00322-7.

Peterson, A.T., Papes, M., Kluza, D.A., 2003. Predicting the potential invasive distributions of four alien plant species in North America. Weed Science 51 (6), 863-868.

Peterson, A.T., Papeş, M., Soberón, J., 2008. Rethinking receiver operating characteristic analysis applications in ecological niche modeling. Ecological Modelling 213 (1), 63-72. https://doi.org/10.1016/j.ecolmodel.2007.11.008.

Phillips, S.J., Anderson, R.P., Schapire, R.E., 2006. Maximum entropy modeling of species geographic distributions. Ecological Modelling 190 (3-4), 231-259. https://doi.org/ 10.1016/j.ecolmodel.2005.03.026.

Phillips, S.J., Dudík, M., 2008. Modeling of species distributions with Maxent: new extensions and a comprehensive evaluation. Ecography 31 (2), 161-175. https://doi. org/10.1111/j.0906-7590.2008.5203.x.

Pyron, R.A., Burbrink, F.T., Guiher, T.J., 2008. Claims of potential expansion throughout the US by invasive python species are contradicted by ecological niche models. PLoS One 3 (8), e2931. https://doi.org/10.1371/journal.pone.0002931.

Rivaes, R.P., Rodríguez-González, P.M., Ferreira, M.T., Pinheiro, A.N., Politti, E., Egger, G., García-Arias, A., Francés, F., 2014. Modeling the evolution of riparian woodlands facing climate change in three European rivers with contrasting flow regimes. PLoS One 9 (10), e110200. https://doi.org/10.1371/journal.pone.0110200.

Schippmann, U., Leaman, D.J., Cunningham, A.B., 2002. Impact of cultivation and gathering of medicinal plants on biodiversity: global trends and issues. Biodiversity and the Ecosystem Approach in Agriculture, Forestry and Fisheries. FAO, Rome.

Sharma, S., Arunachalam, K., Bhavsar, D., Kala, R., 2018. Modeling habitat suitability of Perilla frutescens with MaxEnt in Uttarakhand-a conservation approach. Journal of Applied Research on Medicinal and Aromatic Plants 10, 99-105. https://doi.org/10. 1016/j.jarmap.2018.02.003.

Soberón, J., Peterson, A.T., 2005. Interpretation of models of fundamental ecological niches and species' distributional areas. Biodiversity Informatics 2, 1-10.

Swets, J.A., 1988. Measuring the accuracy of diagnostic systems. Science 240, 1285-1293. https://doi.org/10.1126/science.3287615.

Telwala, Y., Brook, B.W., Manish, K., Pandit, M.K., 2013. Climate-induced elevational range shifts and increase in plant species richness in a Himalayan biodiversity epicentre. PLoS One 8 (2), e57103. https://doi.org/10.1371/journal.pone.0057103.

Wan, Z., Hook, S., Hulley, G., 2015. MOD11A2 MODIS/terra land surface temperature/ emissivity 8-day L3 global $1 \mathrm{~km}$ SIN grid V006. NASA EOSDIS Land Processes DAAC 10.

Zhang, K., Yao, L., Meng, J., Tao, J., 2018. Maxent modeling for predicting the potential geographical distribution of two peony species under climate change. Science of the Total Environment 634, 1326-1334. https://doi.org/10.1016/j.scitotenv.2018.04. 112. 